\title{
The effect of aprotinin on luteolytic and uterine contractile mechanisms in the pregnant rat at term
}

\author{
E. T. Whalley and A. J. Riley* \\ Department of Pharmacology, The Medical School, University of Manchester, Oxford Road, \\ Manchester M13 9PT, U.K.
}

\begin{abstract}
Summary. The effect of the kallikrein inhibitor aprotinin on luteal function, uterine activity and parturition was studied in primigravid pregnant rats. Luteal function was monitored by the determination of serum progesterone levels. Aprotinin given daily from Day 19 to Day 22 of gestation had no effect on progesterone concentrations compared to saline-treated controls, but indomethacin delayed the decline in progesterone levels over the same time period. Aprotinin treatment had no effect on fetal and placental weights from Days 19 to 22 of gestation.

Aprotinin infusion in Day-22 pregnant rats resulted in a reduction in uterine motility (studied by continuous recording in conscious rats by means of an intrauterine microballoon) in 10/12 rats. Continuous infusion of aprotinin into rats which had been allowed to deliver one young resulted in a significantly prolonged duration of parturition compared to that in saline-infused controls. In one rat the delivery process was completely arrested and recommenced only when the infusion was stopped.

Aprotinin had no effect on either the spontaneous or oxytocin-induced uterine contractions of the isolated Day-22 pregnant rat uterus.

It is concluded that the kallikrein-kinin system in the late pregnant rat does not appear to be involved in the luteolytic process but may play a functional role in the control of uterine and/or cervical function before and during parturition.
\end{abstract}

\section{Introduction}

The kallikrein-kinin system has been studied during pregnancy and parturition in the rat (McCormick, Senior \& Whalley, 1974), rabbit (Weigerhausen, Klausch, Henninghausen \& Sosat, 1968) and man (Martinez, Carvahlo \& Diniz, 1962; Periti \& Gasparri, 1966; Porter, Shennan \& Smith, 1972; Branconi et al., 1976). These studies have shown that there is an increase in the plasma kinin precursor levels as gestation advances which may be related to changes in the oestrogen-progesterone ratio in the maternal plasma (Senior \& Whalley, 1974). The two actions of kinins that may be involved in the events leading up to the onset of parturition and the parturient process are the local vasodilator and the smooth muscle stimulating effects. It seems possible that lack of either or both these effects could influence parturition. Alteration of the components of the kallikrein-kinin system during pregnancy in the rat can alter the course of pregnancy. Prolongation of both the gestational period and the parturient process can be obtained by administering the kallikrein inhibitor aprotinin to rats in late pregnancy. However, the response produced appears to depend upon the time when aprotinin treatment is commenced (Senior \& Whalley, 1976).

\footnotetext{
* Present address: Medical Division, Glaxo-Allenburys Research, Ware, Hertfordshire SG12 0DJ, U.K.
} 
This study investigates the effects of aprotinin on luteal regression and uterine motility in the late pregnant and parturient rat.

\section{Materials and Methods}

Primigravid Sprague-Dawley rats were used at known stages of gestation, Day 1 being the day spermatozoa were found in the morning vaginal smear.

\section{Effect of aprotinin on progesterone concentrations}

Serum progesterone concentrations were determined (Anderson, Hopper, Lasley \& Yen, $1976)$ in groups of rats treated from Days 19 to 22 of pregnancy with $0.2 \mathrm{ml}$ saline $(0.154 \mathrm{M}$ $\mathrm{NaCl}$ ), aprotinin (25000 ki.u./ $\mathrm{kg}$ twice daily) or indomethacin $(2 \mathrm{mg} / \mathrm{kg} /$ day), all given by subcutaneous injection. Blood was obtained at 12:00 h on each day from the trunk after decapitation and the serum was stored at $-20^{\circ} \mathrm{C}$ until assay. Indomethacin was used as a reference compound since it has been previously reported to delay the decline in progesterone concentrations in late gestation in rats (Fuchs, Smitasiri \& Chantharaksri, 1976).

Progesterone was assayed in duplicate samples of 20 and $100 \mu \mathrm{l}$ serum extracted with $1 \mathrm{ml}$ petroleum ether, by using an antiserum raised in a rabbit against progesterone-2-succinyl-bovine serum albumin. The major cross-reactions of the antiserum are with $5 \alpha$-pregnane-3,20-dione

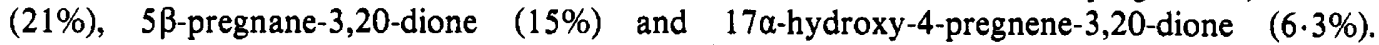
Recovery of tritium-labelled steroid was $73 \%$. Precision and accuracy were assessed by running a pool of steroid-free plasma to which $2000 \mathrm{pg} / \mathrm{ml}$ of the steroid had been added in each assay. The coefficients of variation for samples read on the linear portion of the standard curve, using the $2000 \mathrm{pg} / \mathrm{ml} \mathrm{pool,} \mathrm{were} 7 \%$ (intra-assay) and $12.6 \%$ (inter-assay). The sensitivity of the assay was $12 \mathrm{pg} /$ tube.

After blood sampling for progesterone determination, the uterine horns were exposed, each conceptus was taken out and the fetal membranes carefully removed. The wet weight of each fetus and placenta was recorded.

\section{Effect of aprotinin on uterine activity in vivo and parturition}

To investigate the effect of aprotinin on uterine activity and the process of parturition, groups of Day-19 pregnant rats were prepared, under ether anaesthesia, with (a) an indwelling catheter (i.d. $0.58 \mathrm{~mm}$, o.d. $0.96 \mathrm{~mm}$ : Portex p.p. 50) inserted into the right jugular vein for the administration of drugs, and (b) a microballoon-tipped catheter which was inserted into the ovarian end of the right uterine horn through a small transverse incision which was closed by means of a purse-string suture (5-0 silk) around the catheter (p.p. 50). This was used for recording intrauterine pressure. Both catheters were passed subcutaneously to the back of the neck and exteriorized there through a stainless steel template. Uterine activity was recorded in the conscious, unrestrained animal as previously described (Whalley, 1977).

On Day 22 of gestation a single continuous intravenous infusion of aprotonin, at a rate of $10000 \mathrm{ki} . \mathrm{u} . / \mathrm{kg} \cdot \mathrm{min}^{-1}$ at $0.4 \mathrm{ml} / \mathrm{h}$, for a period of $30-60 \mathrm{~min}$, was performed to determine its effect on uterine motility $(n=12)$.

To determine the effect of aprotinin on the duration of parturition, aprotinin was infused $\left(10000 \mathrm{ki} . \mathrm{u} . / \mathrm{kg} \cdot \mathrm{min}^{-1}\right)$ into rats which had been allowed to deliver one young. The results were compared with those of saline-infused controls. 
Effect of aprotinin on uterine activity in vitro

Uterine horns were removed from Day-22 pregnant rats. Longitudinal muscle strips were mounted in $20 \mathrm{ml}$ tissue baths containing Krebs solution at $37^{\circ} \mathrm{C}$ and bubbled with $95 \% \mathrm{O}_{2}$ and $5 \% \mathrm{CO}_{2}$. The effect of aprotinin $(40,80,160$ and $1600 \mathrm{ki} . \mathrm{u} . / \mathrm{ml})$ was investigated on this spontaneously contracting preparation.

Similar preparations were also set up as above but were bathed with a modified Krebs solution at $34{ }^{\circ} \mathrm{C}$ and bubbled with $95 \% \mathrm{O}_{2}$ and $5 \% \mathrm{CO}_{2}$. The effect of oxytocin was studied on this quiescent preparation in the presence and absence of a range of concentrations of aprotinin $(40-1600$ ki.u./ml).

The composition of the Krebs solution (mM) was: $\mathrm{Na}^{+}, 143 \cdot 5 ; \mathrm{K}+5 \cdot 9 ; \mathrm{Ca}^{2+} 2.6 ; \mathrm{Mg}^{2+}$, $1.2 ; \mathrm{Cl}^{-}, 104.8 ; \mathrm{HCO}_{3}^{-}, 24.9 ; \mathrm{SO}_{4}^{2-}, 1 \cdot 2 ; \mathrm{H}_{2} \mathrm{PO}_{4}^{-}, 2 \cdot 2$; and glucose, $10 \cdot 0$. The composition of the modified Krebs solution was: $\mathrm{Na}^{+}, 143.5 ; \mathrm{K}^{+}, 5.9 ; \mathrm{Ca}^{2+}, 0.64 ; \mathrm{Mg}^{2+}, 1 \cdot 19 ; \mathrm{Cl}^{-}, 124.6$; $\mathrm{HCO}_{3}^{-}, 24 \cdot 9 ; \mathrm{SO}_{4}^{2-}, 1 \cdot 2 ; \mathrm{H}_{2} \mathrm{PO}_{4}^{-}, 1 \cdot 19$; and glucose, 5.65.

\section{Statistical analysis}

The significance of differences between means was assessed by Student's $t$ test.

\section{Results}

\section{Effect of aprotinin on progesterone concentrations}

The serum progesterone concentrations of pregnant rats treated with aprotinin from Days 19 to 22 were not significantly different from levels in control rats between Days 20 and 22 (Table 1). Treatment with indomethacin from Day 19 to Day 22 delayed the decline in serum progesterone levels and concentrations of progesterone on Day 22 of pregnancy were signifcantly higher than those in the controls.

Table 1. Mean \pm s.e.m. serum progesterone levels in pregnant rats (5-6/group) treated with saline, aprotinin ( $25000 \mathrm{ki} . \mathrm{u} . / \mathrm{kg}$

s.c. twice daily) or indomethacin ( $2 \mathrm{mg} / \mathrm{kg} /$ day s.c.)

\begin{tabular}{cccc}
\hline $\begin{array}{c}\text { Day of } \\
\text { gestation } \\
(12: 00 \mathrm{~h})\end{array}$ & \multicolumn{3}{c}{ Progesterone (ng/ml) } \\
\cline { 2 - 4 } & Saline (control) & Aprotinin & Indomethacin \\
\hline 19 & $95.8 \pm 4.6$ & & \\
20 & $80.7 \pm 5.4$ & $75.0 \pm 4.6$ & $83.5 \pm 11.3$ \\
21 & $53.9 \pm 5.1$ & $44.2 \pm 2.4$ & $61.2 \pm 9.3$ \\
22 & $30.9 \pm 3.9^{*}$ & $33.8 \pm 1.6$ & $51.0 \pm 4.7^{*}$ \\
\hline
\end{tabular}

* Significantly different, $P<0.05$.

The effect of aprotinin on fetal and placental weight was studied using the animals treated for determination of serum progesterone. Aprotinin treatment had no significant effect on fetal or placental weight compared to control values over the period studied.

\section{Effect of aprotinin on uterine activity in vivo and parturition}

The effect of an infusion of aprotinin on uterine activity in a Day-22 pregnant rat can be seen in Text-fig. 1. There was a gradual reduction in activity but when the infusion was stopped normal activity quickly returned. This effect was seen in 10 out of 12 rats and was most evident in rats exhibiting regular cyclic uterine activity. Complete inhibition of uterine motility was never seen. 


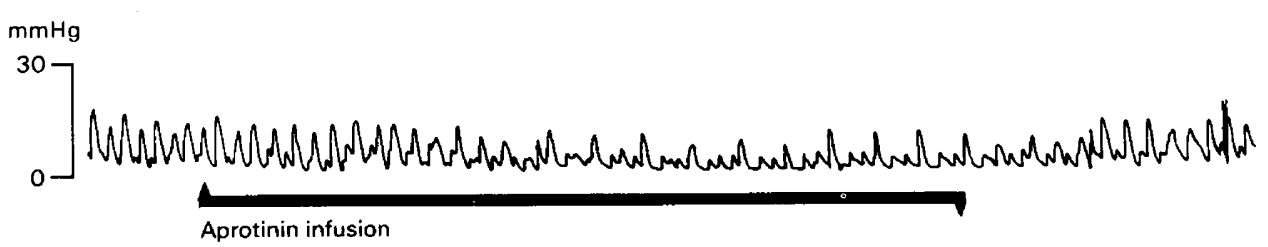

Text-fig. 1. Effect of an intravenous infusion (solid line) of aprotinin $\left(10000 \mathrm{ki} . \mathrm{u} . / \mathrm{kg} \cdot \mathrm{min}^{-1}\right)$ on intrauterine pressure in a Day-22 conscious pregnant rat.

Infusion of aprotinin into rats after delivery of the first young resulted in a significantly prolonged parturient period compared to that for saline-infused controls. The results are summarized in Table 2. There was no difference in the number of still-born young. Text-figure 2(a) shows the pattern of uterine activity observed during a saline control infusion during the parturient period and can be compared with the activity in a rat infused with aprotinin (Text-fig. 2b). After an initial inhibition of delivery between the first few young after the start of the infusion all the young were eventually born.

Table 2. Effect of an intravenous infusion of saline and aprotinin $\left(10000 \mathrm{ki.u} . / \mathrm{kg} \cdot \mathrm{min}^{-1}\right)$ on the duration of parturition in the rat after birth of the first young

\begin{tabular}{lcccccc}
\hline \multicolumn{1}{c}{ Treatment } & $\begin{array}{c}\text { No. of } \\
\text { rats }\end{array}$ & $\begin{array}{c}\text { Duration of } \\
\text { parturition } \\
(\mathrm{min})\end{array}$ & $\begin{array}{c}\text { Time for } \\
\text { each young } \\
(\mathrm{min})\end{array}$ & $\begin{array}{c}\text { Total no. } \\
\text { of young }\end{array}$ & $\begin{array}{c}\text { No. of young } \\
\text { born dead }\end{array}$ & $\begin{array}{c}\text { Mean no. of } \\
\text { young/rat }\end{array}$ \\
\hline Saline (control) & 12 & $81 \cdot 8 \pm 5 \cdot 1$ & $7.5 \pm 0.2$ & 139 & 4 & $11.6 \pm 0.5$ \\
Aprotinin & 11 & $108 \cdot 0 \pm 5 \cdot 4^{*}$ & $10.4 \pm 0.4^{*}$ & 136 & 3 & $12.4 \pm 0.6$ \\
\hline
\end{tabular}

* Significantly different from value for saline control group, $P<0.05$.

In one rat infused with aprotinin, the parturient process was completely arrested. It was observed that during periods of aprotinin infusion no young were born and uterine motility was markedly reduced. Only when the infusion was stopped did uterine motility increase and parturition recommence. Infusion of aprotinin was discontinued after $160 \mathrm{~min}$ and the rat then gave birth to the whole litter, all of which were alive.

\section{Effect of aprotinin on uterine activity in vitro}

Aprotinin did not have any effect on the spontaneous or oxytocin-induced uterine contractions in vitro of the Day-22 pregnant rat.

\section{Discussion}

Alteration of the components of the kallikrein-kinin system in the rat can modify the course of pregnancy (McCormick et al., 1974). Prolongation of both the gestational period and parturition can be obtained by administration of the kallikrein inhibitor aprotinin to pregnant rats from Day 19 to Day 22. However, if treatment is started on any day after Day 19 then only the parturient period is prolonged with no effect on the duration of gestation (Senior \& Whalley, 1976). In this study aprotinin reduced the motility of the uterus of the Day-22 pregnant conscious rat in the majority of animals. When aprotinin was infused continuously during parturition after the first young had been delivered, a significant prolongation of the delivery period resulted. Unfortunately dose-response relationships of aprotinin on uterine activity and the process of parturition were not performed because there was insufficient freeze-dried material. 

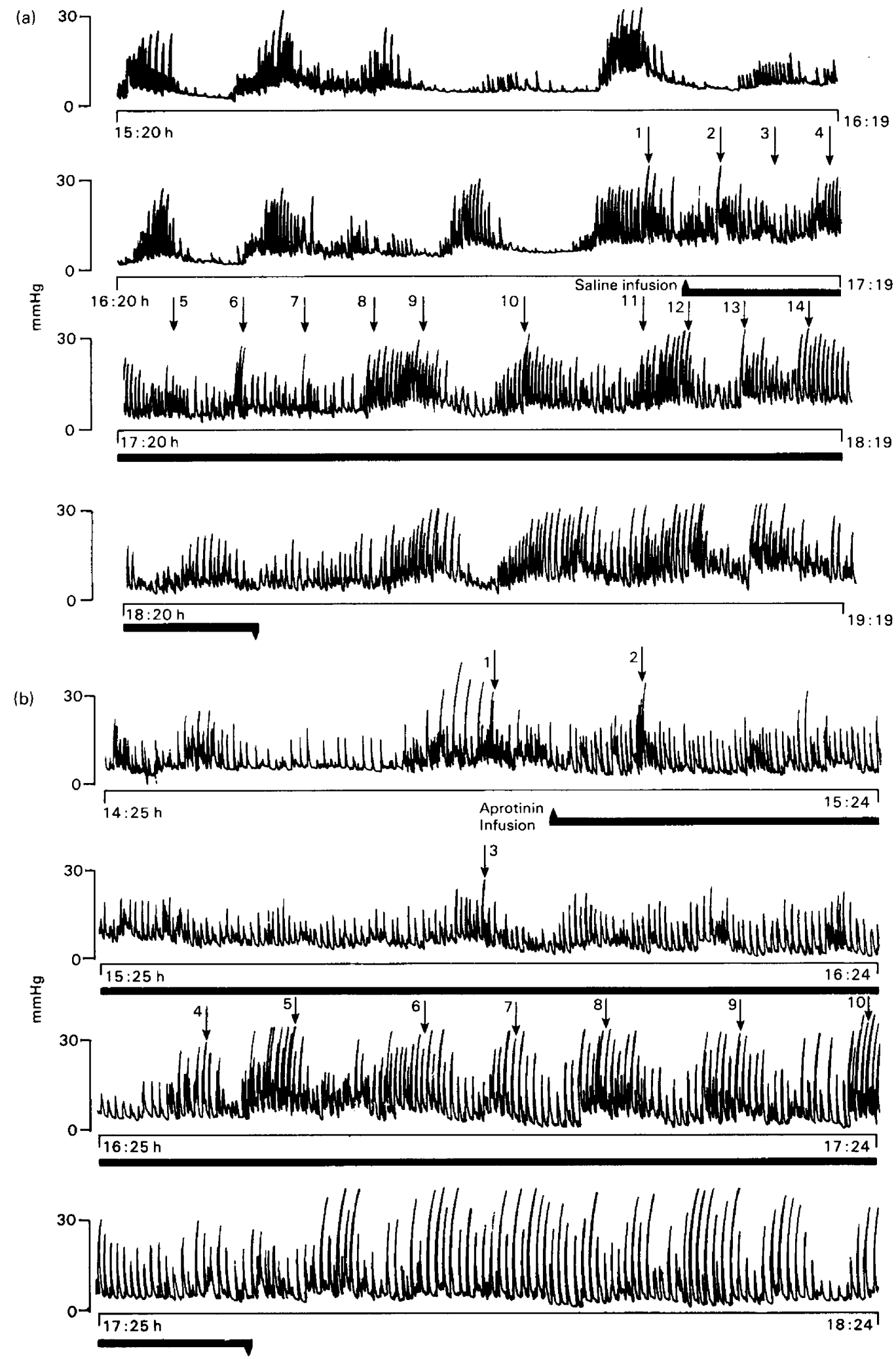

Text-fig. 2. The effect of intrauterine pressure changes in the rat during parturition when (a) saline and (b) aprotinin (10 $\left.000 \mathrm{ki} . \mathrm{u} . / \mathrm{kg} \cdot \mathrm{min}^{-1}\right)$ are dnfused (solid bar) . The times of delivery of $_{1: 35: 05 \mathrm{PM}}$ the fetuses and placentae are indicated. 
These studies suggest that aprotinin, possibly by its kallikrein inhibitory activity, interferes with the physiological processes in which kinins are functionally involved. The two actions of kinins which may be involved are the local vasodilator and the smooth muscle-stimulating effects. The rat uterus is very sensitive to bradykinin and its action on the oestrous uterus in vitro involves a significant direct action on the myometrium and a "prostaglandin component" (Whalley, 1978). The uterotonic action of bradykinin is also significantly enhanced by prostaglandin F-2 $\alpha$. The increased capacity of the pregnant rat uterus to synthesize prostaglandins at term (Vane \& Williams, 1973; Williams, Sneddon \& Harney, 1974; Harney, Sneddon \& Williams, 1974; Chan, 1977), and mobilization of the kinin system which is thought to occur in late pregnancy and parturition in the rat (McCormick \& Senior, 1974), could result in activation of the uterus at term, involving direct and indirect actions of kinins.

The uterotonic action of bradykinin in vivo is unclear. Berde \& Saameli (1961) have demonstrated no effect of bradykinin in women shortly before or after parturition. However, bradykinin was given intravenously and it is most likely that since the peptide is very efficiently inactivated during passage through the pulmonary circulation (Ferreira \& Vane, 1967), very little reached the uterus to produce an effect.

Since a vasodilator role for the kinins in myometrial physiology has been postulated (Periti \& Gasparri, 1966) aprotinin may interfere with uterine contractile mechanisms indirectly via a reduction in blood flow in the uterine environment. Phaily \& Senior (1978) have demonstrated that aprotinin significantly reduces the oestrogen-induced increase in uterine blood flow in ovariectomized non-pregnant rats. This would reduce the myometrial stimulant action of other circulating agents, in particular, oxytocin which is known to be present in increased concentrations at term (Fuchs \& Saito, 1971; Chard, 1972). The uterotonic action of oxytocin in urethane-anaesthetized Day-22 pregnant rats is reduced by prior infusion of aprotinin (A. J. Riley \& E. T. Whalley, unpublished observations). A direct uterine depressant action of aprotinin is unlikely since the compound over the dose range used was found to have no effect on either the spontaneous or oxytocin-induced uterine contractions of the isolated Day-22 pregnant rat uterus.

Aprotinin may also interfere indirectly with the release of oxytocin from the pituitary. Milk ejection by bradykinin has been demonstrated in ewes and goats (Houvenaghel \& Peeters, 1967; Houvenaghel, Peeters \& Djordjevic, 1968). Whether this is a result of a direct action of bradykinin on the myo-epithelial cells or via release of oxytocin is unclear. In dogs it has been suggested that kinins stimulate the hypothalamo-pituitary system to discharge the related peptide, antidiuretic hormone, with consequent effects on the kidney (Rocha e Silva \& Malnic, 1964; Harris \& Rocha e Silva, 1966). However, there is no evidence that bradykinin acts on the myometrium through the release of oxytocin in the rat (Bisset, Clark, Haldar, Harris, Lewis \& Rocha e Silva, 1967).

One or several of the above proposed mechanisms may be involved in producing aprotinin's uterine inhibitory effect. It must be noted, however, that complete inhibition of uterine motility was never seen and in only one rat was parturition completely inhibited. This is in contrast to previous reports which have shown that an infusion of aprotinin is capable of arresting both normal and premature labour in women (Goisis \& Lami, 1973; Konopka, Afchain \& Seneze, 1973).

The biochemical processes leading to parturition are thought to be triggered around Day 19 of gestation in the rat (Dukes, Chester \& Atkinson, 1974). Since aprotinin was only able to prolong the gestational period when given from Day 19 onwards (Senior \& Whalley, 1976) this may implicate an interference with the luteolytic mechanism. However, the observation that treatment of pregnant animals with aprotinin from Day 19 to Day 22 in this study did not have any effect on serum progesterone concentrations suggests that kinins are not involved in the luteolytic mechanism. This is in contrast to the prostaglandin synthetase inhibitor, indomethacin, which has been shown to delay the onset and prolong the duration of parturition in rats (Aiken, 
1972; Chester, Dukes, Slater \& Walpole, 1972). This drug was demonstrated to delay the decline in progesterone levels in a fashion similar to that described previously by Fuchs et al. (1976). These workers concluded from their experiments that indomethacin exerts its effect in pregnant rats through inhibition of luteal regression and that indomethacin does not have a direct effect on spontaneous or oxytocin-induced myometrial activity in vivo.

In conclusion, aprotinin, a kallikrein inhibitor which prevents the production of kinin, previously shown to prolong gestation in the rat, does not affect luteolytic mechanisms or affect fetal and placental weights. However, uterine motility is reduced and the parturient period prolonged by infusion of aprotinin. The mechanism whereby aprotinin produces these effects may be a consequence of a reduced production of free kinin via inhibition of kallikrein. Kinins are known to have both a uterine stimulant and a local vasodilator effect. After aprotinin, it is possible that there is reduced uterine stimulation as a result of decreased kinin production and a reduced passage of other uterotonic stimulants such as oxytocin to the uterus as a consequence of a reduction in blood flow to the uterus.

We are grateful to Dr D. Anderson and Dr D. Bu'Lock of the Department of Medicine, Hope Hospital, Manchester, for the radioimmunoassay of progesterone and to Professor $G$. Haberland of Bayer, Germany, for the generous gift of freeze-dried aprotinin.

\section{References}

Aiken, J.W. (1972) Aspirin and indomethacin prolong parturition in rats: evidence that prostaglandins contribute to expulsion of foetus. Nature, Lond. 240, $22-25$.

Anderson, D.C., Hopper, B.R., Lasley, B.L. \& Yen, S.S.C. (1976) A simple method for the assay of eight steroids in small volumes of plasma. Steroids $\mathbf{2 8}$, $179-196$.

Berde, B. \& Saameli, K. (1961) Effect of bradykinin on uterine activity. Nature, Lond. 191, 83.

Bissett, G.W., Clark, B.J., Haldar, J., Harris, M.C., Lewis, G.P. \& Rocha e Silva, M. (1967) The assay of milk ejecting activity in the lactating rat. $B r . J$. Pharmac. 31, 537-542.

Branconi, F., Faldi, P., Servalli, G., Curradi, C., Del Bianco, P.L. \& Sicuteri, F. (1976) Plasmatic prekallikrein and kallikrein inhibitor in pregnancy, labour and the new born. In Advances in Experimental Medicine \& Biology 70, 261-263. Eds F. Sicuteri, N. Back \& G. L. Haberland. Plenum Press, New York.

Chan, W.Y. (1977) Relationship between the uterotonic action of oxytocin and prostaglandins: oxytocin action and release of PG-activity in isolated nonpregnant and pregnant rat uteri. Biol. Reprod. 17, $541-548$.

Chard, T. (1972) The role of the posterior pituitary in human and animal parturition. J. Reprod. Fert., Suppl. 16, 121-138.

Chester, R., Dukes, M., Slater, S.R. \& Walpole, A.L. (1972) Delay of parturition in the rat by antiinflammatory agents which inhibit the biosynthesis of prostaglandins. Nature, Lond. 240, 37-38.

Dukes, M., Chester, R. \& Atkinson, P. (1974) Effects of oestradiol and prostaglandin $F_{2}$ on the timing of parturition in the rat. J. Reprod. Fert. 38, 325-334.

Ferreira, S.H. \& Vane, J.R. (1967) The disappearance of bradykinin and eldoisin in the circulation and vascular beds of the cat. Br.J. Pharmac. Chemother. 30, 417-424.

Fuchs, A.R. \& Saito, S. (1971) Pituitary oxytocin and vasopressin content of pregnant rats before, during and after parturition. Endocrinology 88, 574-578.

Fuchs, A.R., Smitasiri, Y. \& Chantharaksri, U. (1976) The effect of indomethacin on uterine contractility and luteal regression in pregnant rats at term. $J$. Reprod. Fert. 48, 331-340.

Goisis, M. \& Lami, V. (1973) Nuovi indirizzi eziopatogenetici e terapeutici in tema di minacce d'aborto. Minerv. Ginecol. 25, 481-492.

Harney, P.J., Sneddon, J.M. \& Williams, K.I. (1974) The influence of ovarian hormones upon the motility and prostaglandin production of the pregnant rat uterus in vitro. J. Endocr. 60, 343-351.

Harris, M.C. \& Rocha e Silva, M., Jr (1966) A central effect of bradykinin in stimulating release of antidiuretic hormone. J. Physiol., Lond. 183, 28-29P.

Houvenaghel, A. \& Peeters, G. (1967) Influence del la bradykinine sur l'ejection du lai chez la brebis et la chèvre. Archs int. Pharmacodyn. 169, 483-489.

Houvenaghel, A., Peeters, G. \& Djordjevic, N. (1968) Influence de kinines du plasma et des kallikreins sur l'ejection du lait chez la brebis. Archs int. Pharmacodyn. 171, 231-237.

Konopka, P., Afchain, J. \& Seneze, J. (1973) Essai d'explication du mechanisme du travail. Rev. Franc. Gynecol. 68, 7-12.

Martinez, A.R., Carvahio, I.F. \& Diniz, C.R. (1962) The bradykininogen content of plasma from women in labour. J. Obstet. Gynaec. Br. Commonw. 69, 10111014.

McCormick, J.T. \& Senior, J. (1974) Plasma kinin and kininogen levels in the female rat during the oestrous cycle, pregnancy, parturition and the puerperium. Br. J. Pharmac. 50, 237-241.

McCormick, J.T., Senior, J. \& Whalley, E.T. (1974) 
Changes in plasma kininogen levels induced by cellulose sulphate during pregnancy in the rat. $\mathrm{Br} . J$. Pharmac. 52, 533-537.

Periti, P. \& Gasparri, F. (1966) Bradykininogen in the blood of women during pregnancy, labour and the puerperium. In Hypotensive Peptides, pp. 536-539. Eds E. G. Erdos, N. Back, F. Sicuteri \& A. F. Wilde. Springer, Berlin.

Phaily, S. \& Senior, J. (1978) Modification of oestrogeninduced uterine hyperaemia by drugs in the ovariectomized rat. J. Reprod. Fert. 53, 91-97.

Porter, J.F., Shennan, A.T. \& Smith, S. (1972) Plasma kinin levels in women during pregnancy and labour. J. Reprod. Fert. 30, 247-254.

Rocha e Silva, M., Jr \& Malnic, G. (1964) Release of antidiuretic hormone by bradykinin. J. Pharmac. exp. Ther. 146, 24-32.

Senior, J. \& Whalley, E.T. (1974) Variation in the oestrogen-progesterone ratio and its effect on plasma kininogen levels in the rat. J. Reprod. Fert. 41, 425433.

Senior, J. \& Whalley, E.T. (1976) The influence of drugs on the kinin-forming system in relation to pregnancy and parturition in the rat. J. Reprod. Fert. 47, 319323.

Vane, J.R. \& Williams, K.I. (1973) The contribution of prostaglandin production to contractions of the isolated uterus of the rat. Br. J. Pharmac. 48, 629639.

Weigerhausen, B., Klausch, B., Henninghausen, G. \& Sosat, R. (1968) Der Kininogenspiegel von Ratten und Kaninchen wahrend der Gestation. Experientia 24, $1128-1129$.

Whalley, E.T. (1977) The cardiovascular and uterine effects of labetolol in conscious normotensive pregnant rats. Br. J. Pharmac. 61, 505-506P.

Whalley, E.T. (1978) The action of oxytocin and bradykinin on the isolated whole uterus and myometrium of the rat in oestrus. Br.J. Pharmac. 64, 21-28.

Williams, K.I., Sneddon, J.M. \& Harney, P.J. (1974) Prostaglandin production by the pregnant rat uterus in vitro and its relevance to parturition. Pol. $J$. Pharmac. Pharm. 26, 207-215.

Received 26 June 1978 